\title{
Models and mechanisms of anxiety: evidence from startle studies
}

\author{
Christian Grillon
}

Received: 2 July 2007 / Accepted: 7 November 2007 /Published online: 6 December 2007

(C) Springer-Verlag 2007

\begin{abstract}
Rationale Preclinical data indicates that threat stimuli elicit two classes of defensive behaviors, those that are associated with imminent danger and are characterized by flight or fight (fear), and those that are associated with temporally uncertain danger and are characterized by sustained apprehension and hypervigilance (anxiety).

Objective The objectives of the study are to (1) review evidence for a distinction between fear and anxiety in animal and human experimental models using the startle reflex as an operational measure of aversive states, (2) describe experimental models of anxiety, as opposed to fear, in humans, (3) examine the relevance of these models to clinical anxiety.

Results The distinction between phasic fear to imminent threat and sustained anxiety to temporally uncertain danger is suggested by psychopharmacological and behavioral evidence from ethological studies and can be traced back to distinct neuroanatomical systems, the amygdala and the bed nucleus of the stria terminalis. Experimental models of anxiety, not fear, are relevant to non-phobic anxiety disorders. Conclusions Progress in our understanding of normal and abnormal anxiety is critically dependent on our ability to model sustained aversive states to temporally uncertain threat.
\end{abstract}

C. Grillon

Unit of Affective Psychophysiology, Mood and Anxiety

Disorder Program, Intramural Research Program,

National Institute of Mental Health,

National Institutes of Health,

Bethesda, MD, USA

C. Grillon $(\triangle)$

NIMH/MAP,

15K North Drive, Bldg 15K, Room 113, MSC 2670,

Bethesda, MD 20892-2670, USA

e-mail: Christian.grillon@nih.gov
Keywords Startle $\cdot$ Fear-potentiated startle $\cdot$ Fear $\cdot$ Anxiety Experimental models $\cdot$ Anxiety disorders

\section{Introduction}

Preclinical research in animals has been instrumental to our current understanding of anxiety and anxiety disorders, outlining neural and psychopharmacological mechanisms of defensive responses to threat. Major obstacles remain, however, in translating animal experiments into human research and increase our knowledge of anxiety and its dysfunction. One aspect of anxiety research in need of closer scrutiny is the nature of the defensive state under study in various experimental paradigms. Pioneering work by Michael Davis and colleagues in rodents demonstrates that there are two primary defensive behavioral states subserved by distinct neural substrates, fear, a phasic response to imminent threat mediated by the amygdala, and anxiety, a sustained response to temporally uncertain danger mediated by the bed nucleus of the stria terminalis (for a review, see Walker et al. 2003). Using the startle reflex as the primary operationalization of these defensive states, Davis and colleagues have presented abundant evidence of such a neuroanatomical dissociation by ablation and pharmacological manipulation. The objective of this review is to examine the extent to which findings from startle research in humans also support a similar distinction between fear and anxiety and describe lab-based procedures to study sustained anxiety. In the end, we argue that mechanisms underlying sustained, as opposed to phasic aversive states, are particularly relevant to anxiety disorders and that progress toward elucidating clinical anxiety will be facilitated by adopting and incorporating this conceptual framework into human experimental paradigms. 
Discriminating fear from anxiety

Anticipation of and preparation for future harm are central features of fear and anxiety. These defensive responses adaptively organize behavior to deal with threats that endanger the integrity of the organism. In animals, defensive responses vary greatly with the nature of the danger; they depend on whether the threat is present and requires immediate action or is only temporally uncertain or distal and leads to enhanced and sustained vigilance (Blanchard et al. 1993). These responses to threat are well conserved across species and are evolutionary precursors to human fear and anxiety, defined as a phasic emergency reaction to an imminent threat and a sustained state of heightened vigilance and apprehension, respectively. Because of overlapping characteristics, distinguishing fear and anxiety has been difficult and controversial (McReynolds 1976; Sarbin 1964). However, reducing anxiety to fear impedes research efforts aimed at better understanding normal and pathological anxiety.

Converging evidence from different levels of analysis supports the conception of fear and anxiety as distinct phenomena. First, clinicians generally accept the distinction between fear, a response to an impending identifiable danger and anxiety, a state of chronic apprehension about future harm, characterized by tension, worry, negative affect, and a feeling of insecurity (Barlow 2000; Rachman 2004). Fear is a surge of physiological arousal, an alarm reaction resulting in reflexive action, fight or flight when possible, or aimed at reducing the impact of the threat, for example, by decreasing pain sensitivity (Blanchard et al. 1993; Bolles and Fanselow 1980; Carlsson et al. 2006; Rhudy and Meagher 2000) when action is thwarted. In contrast, anxiety is elicited by unpredictability and by the perception of potential, unseen, or symbolic threats. Behaviorally, anxiety is associated with avoidance. Fear narrows attention and inhibits competing responses (Mowrer and Aiken 1954), whereas anxiety increases overall sensory sensitivity (Baas et al. 2004b; Cornwell et al. 2007). Second, the distinction between fear and anxiety is supported by psychometric analyses of anxious symptomatology that distinguish symptoms of general distress and anxious apprehension (anxiety) from those of arousal and fight/flight (fear) (Brown et al. 1998; Zinbarg and Barlow 1996). Of note, anxious apprehension is a diagnostic feature that cuts across anxiety disorders, with the possible exception of specific phobia (Barlow and Di Nardo 1991). Third, ethological studies have linked fear to behaviors elicited by actual danger (presence a predator) and anxiety to responses to distal or potential threats (predator odor). Fear is characterized by flight or fight and anxiety by 'risk assessment' behaviors (Blanchard et al. 1993; Rodgers 1997). Fear and anxiety, defined in terms of phasic and sustained states, have different pharmacological profiles.
Risk assessment (anxiety) is sensitive to benzodiazepines, whereas the defensive response to an imminent danger (fear) is not (Blanchard et al. 1993). The fourth, and arguably one of the most compelling lines of evidence for a distinction between fear and anxiety comes from preclinical fearpotentiated startle studies that suggest that, notwithstanding substantial overlap, there is also a clear and distinct differentiation between neural systems mediating short- and long-duration aversive states.

Startle as a translational index of fear and anxiety

One key to furthering our knowledge of anxiety in humans is the implementation of experimental models in healthy humans that can serve as a bridge between preclinical investigations and clinical research. Because experimental models of anxiety in animals are far ahead of human models in terms of data and theories, these models constitute a rich source of information to guide research in humans. Animal models of anxiety based on the startle reflex are especially promising for translational studies. The startle reflex is a ubiquitous, cross-species response to abrupt and intense stimulation. It consists of a rapid sequential muscle contraction with the likely purpose of facilitating the flight reaction and/or to protect the body from a sudden attack. The 'startle pattern' consists of a forward thrusting of the head and a descending flexor wave reaction, extending through the trunk and the knees (Landis and Hunt 1939). Startle is stereotyped, but not invariant. In animals and humans, fear and anxietyinducing stimuli or administration of anxiogenic agents increase startle. Startle is also exaggerated in patients with an anxiety disorder (Butler et al. 1990; Grillon et al. 1994, 1998c) and reduced in psychopathic individuals (Patrick et al. 1993). The value of startle includes its face validity as a probe of aversive states and the convergence and similarities of experiments that can be conducted in humans and in rodents (Grillon and Baas 2003). Furthermore, the neurobiological substrates of startle plasticity by aversive states are fairly well-delineated (Walker et al. 2003), allowing for greater hypothesis testing and generalizability of the results (Risbrough and Stein 2006). Finally, as an automatic/ reflexive subcortical measure, startle may be less influenced by intentional control and more resistant to demand characteristics than verbal reports.

Preclinical evidence for dissociated neural systems of fear and anxiety

To date, data based on the startle reflex provide the most compelling evidence for a differentiation between neural systems mediating phasic/short-duration (several seconds to tens of seconds) aversive states and sustained/long-duration aversive states (a minute and several minutes) (for a review, 
see Walker et al. 2003). While the amygdala is pivotal to responses to a discrete threat cue, a related structure, the bed nucleus of the stria terminalis (BNST), is crucial for anxiety responses to temporally uncertain danger (Walker et al. 2003). The BNST is adjacent to the anterior commissure in the basal forebrain and makes up the rostral portion of the neural continuum known as the extended amygdala. The BNST resembles the amygdala in terms of cell morphology and neurotransmitters (Alheid et al. 1998). Both the central nucleus of the amygdala $(\mathrm{CeA})$ and the BNST receive highly processed information from the basolateral nuclei of the amygdala and send similar downstream connections to brain structures that mediate the expression of fear and anxiety (Walker et al. 2003). Because of these similar downstream convergences, it may be difficult to clearly differentiate physiological and behavioral responses orchestrated by the CeA and the BNST.

The hypothesis of dissociable neural systems underlying short-duration and long-duration aversive states is supported by findings from various experimental paradigms. Phasic fear-potentiated startle responses are mediated by the amygdala, not by the BNST. Post-training lesions of the basolateral amygdala block fear-potentiated startle to a 3.7-s duration conditioned visual stimulus (CS; Sananes and Davis 1992). Similar results have been found with a short-duration auditory CS (Campeau and Davis 1995). Post-training lesions of the CeA also block fear-potentiated startle to a short-duration CS (Campeau and Davis 1995; Hitchcock and Davis 1986). Contrasting with these results, lesions or inactivation of the BNST do not affect fearpotentiated startle to a short-duration CS (Gewirtz et al. 1998; Walker and Davis 1997a).

The BNST does not mediate phasic fear-potentiated startle to a discrete cue, but it is involved in sustained forms of potentiated startle. Rats are nocturnal species and are naturally afraid of illuminated environments, probably because such environments require continual monitoring for sources of potential danger. This anxiogenic reaction to lights is reflected by increased startle in lighted places compared to dark places (light-enhanced startle; de Jongh et al. 2003; Walker and Davis 1997b), an effect blocked by anxiogenic drugs (Walker and Davis 1997b, 2002a). Light-enhanced startle depends on the BNST, not the CeA. Infusions of the alpha-amino-3-hydroxy-5-methyl-4-isoxazolepropionate (AMPA) receptor antagonist 1,2,3,4-tetrahydro-6-nitro-2,3dioxo-benzo[f]quinoxaline-7-sulfonamide (NBQX) into the $\mathrm{CeA}$, which blocks fear-potentiated startle to a conditioned fear cue, leaves the light-enhanced startle unaffected (Walker and Davis 1997a). In contrast, infusions of NBQX into the BNST abolishes light-enhanced startle. These experiments demonstrate a double dissociation between the role of the $\mathrm{CeA}$ and the BNST in two forms of potentiated startle to aversive stimuli or conditions.
Certainty of danger is a crucial distinguishing factor between fear-potentiated startle and light-enhanced startle. Light-enhanced startle is associated with a potential and temporally uncertain threat, leading to a sustained aversive state. In contrast, fear-potentiated startle is a phasic reaction to a real and predictable danger. Another model, the shock sensitization of startle, bears similarities to the lightenhanced startle. Shock sensitization of startle consists in a long-lasting increase in startle reactivity that develops when rats receive repeated footshocks over several days (Gewirtz et al. 1998). This sensitization is also mediated by the BNST, not by the CeA (Gewirtz et al. 1998).

Further evidence for a role of the BNST in sustained aversive states comes from studies with the stress hormone corticotrophin releasing hormone (CRH). Beyond its longestablished functional role in stress-induced endocrine, autonomic, and behavioral responses via action at the hypothalamic-pituitary-adrenal (HPA) axis, CRH supports anxiety, via widespread CRH-containing neurons at extrahypothalamic sites, in particular, in limbic structures (Makino et al. 1994a,b). Dysregulation of CRH activity has been linked to anxiety and mood disorders (Carroll et al. 1976; McEwen 2005; Shea et al. 2005), and acute and chronic treatment with $\mathrm{CRH}$ in rodents results in potentiation of anxiety-like responses in a number of behavioral assays of anxiety (Adamec and McKay 1993; Diamant et al. 1992; Sherman and Kalin 1988). In contrast, CRH antagonists abolish stress-induced potentiation of anxiety (Korte and De Boer 2003).

Here again, startle studies provide clues as to the mechanisms of action of $\mathrm{CRH}$ in sustained anxiety. Infusion of $\mathrm{CRH}$ into the lateral ventricle produces a dose-dependent facilitation of startle lasting up to several hours (Risbrough et al. 2003; Swerdlow et al. 1986), which can be blocked by anxiolytic drugs (Swerdlow et al. 1986). In the mouse, selective inhibition of $\mathrm{CRH}_{1}$ and $\mathrm{CRH}_{2}$ receptors markedly inhibits $\mathrm{CRH}$-enhanced startle, suggesting that both receptors contribute to the anxiogenic effect of CRH (Risbrough et al. 2003). Furthermore, knockout mice for either the $\mathrm{CRH}_{1}$ or the $\mathrm{CRH}_{2}$ receptors show no impairment in fear-potentiated startle, suggesting that activation of these receptor is not required for fear to a discrete cue (Risbrough et al. 2007).

Like light-enhanced startle and the shock-sensitization of startle, CRH-enhanced startle is mediated by the BNST, not the CeA. Chemical lesions of the BNST, but not lesions of the amygdala or of the ventral hippocampus, prevent CRHenhanced startle (Lee and Davis 1997). Infusion of CRH in the BNST, but not in the amygdala mimics the ICV CRH effect (Liang et al. 1992), and infusion of the CRH-receptor antagonist alpha-helical CRH in the BNST blocks CRHenhanced startle (Lee and Davis 1997). These results implicate the BNST rather than amygdala as the primary 
source for the anxiogenic effect of $\mathrm{CRH}$ on startle, pointing to a selective role of CRH in the BNST as a potential mechanism for anxiety states. Consistent with this, administration of alpha-helical CRH in the BNST, but not the amygdala, blocks the sustained facilitation of startle by bright lights, but does not affect fear-potentiated startle to a threat cue (de Jong et al. 2002).

Collectively, these results suggest a differential involvement of the CeA and BNST in phasic vs sustained forms of startle potentiation reflecting responses to temporally certain and uncertain threat, respectively. An alternative interpretation is that the CeA and the BNST mediate conditioned and unconditioned fear responses, respectively. Indeed, phasic startle potentiation (i.e., fear-potentiated startle) is obtained in aversive conditioning studies, whereas light-enhanced startle, shock sensitization of startle, and CRH-enhanced startle are unconditioned responses. However, recent studies relying on measures of anxiety other than startle have also demonstrated the role of BNST in sustained forms of aversive conditioning such as context conditioning (Sullivan et al. 2004) and long-duration conditioned stimuli (Waddell et al. 2006), suggesting that the BNST is involved in sustained aversive states rather than unconditioned responses per se.

In summary, these data demonstrate that the amygdala and the BNST belong to the critical circuit underlying responses to threat and danger, but that they are involved in different aspects of the response. In particular, the BNST is involved in adaptive sustained aversive states to innate and conditioned defensive responses.

\section{Fear and anxiety in anxiety disorders}

Anxiety disorders are heterogeneous, presenting distinct and overlapping characteristics recognized in the various editions of the DSM (American Psychiatric Association 1994). Fear and anxiety overlap, to some extent, across anxiety disorders. While specific phobia could be viewed as the archetype of a 'fear disorder', generalized anxiety disorder is the prototype of an 'anxiety disorder'. However, other disorders are characterized by symptoms of both fear and anxiety. Thus, individuals with posttraumatic stress disorder not only suffer from conditioned fear symptoms to discrete cues that act as reminders of the trauma, but they also exhibit persistent symptoms of sustained anxiety (e.g., hypervigilance, increased startle; American Psychiatric Association 1994). Similarly, a hallmark of panic disorder is the experience of panic attacks, episodes of surge of extreme fear with a feeling of impending doom (American Psychiatric Association 1994). But another key element of the disorder is anxiety, caused by persistent symptoms of apprehensive anticipation and continuous worry focused on the reoccurrence of future panic attacks (Bouton et al.
2001). In addition, one would also expect phobic individuals to exhibit sustained anxiety when anticipating a future confrontation with their phobic objects. If fear and anxiety states are mediated by different neural systems, it should be possible to differentiate pharmacologically among them and develop anxiolytics that specifically target anxiety disorder with dysregulation of one or the other state. For example, drugs that are developed to target fear should relieve phobias. Similarly, drugs that target anxiety should be efficient in the treatment of generalized anxiety disorders. Anxiety disorders that are characterized by both fear and anxiety should benefit from treatments that target both types of symptoms.

Laboratory-based procedure to study sustained anxiety in humans

Various animal models can be replicated in humans. Among them, models based on aversive conditioning have long been established in both species. When combined with the startle methodology, aversive conditioning experiments insure a translational approach rich in theories and neurobiological hypotheses derived from preclinical work. In humans, aversive conditioning studies have largely focused on phasic conditioned fear to discrete cues, but conditioning processes can also generate sustained anxiety responses in humans.

\section{Context conditioning}

During aversive conditioning in which a discrete conditioned stimulus (CS) is paired with an aversive unconditioned stimulus (US, e.g., a shock), fear and anxiety develop to the discrete cue and to the environmental context. Cued and context conditioning differ qualitatively in the way they temporally predict danger and, consequently, activate different classes of defensive responses. A conditioned fear cue is a precise time-dependent predictor of an imminent threat. In contrast, the various static stimuli that constitute the context are continuous reminders of danger without signaling its time of occurrence, leaving the organism in a sustained state of anxiety. Aversive conditioning thus leads to the conditioning of either phasic fear or sustained anxiety depending on whether the danger is predicted by a discrete cue or by the context.

Research on context conditioning in humans is in its infancy. Existing studies rely on several approaches. The simplest consists of changing simple features of the experimental context. For example, auditory stimuli can be used as CS, while changes in the screen color of a monitor provide the conditioning context (Armony and Dolan 2001). Context changes can also be implemented by modifying ambient lighting conditions and/or by playing 
different background noises (Effting and Kindt 2007; Neumann et al. 2007; Neumann 2006; Vansteenwegen et al. 2005). It is unclear how these studies relate to animal investigations. In animal studies, the context usually refers to a spatial location with numerous sources of multimodal sensory information, the complexity of which appears to be a critical determinant of hippocampus involvement in context conditioning (Moses et al. 2007).

Other studies that use different experimental rooms as contexts (Labar and Phelps 2005) do not investigate context conditioning per se, but focus on the impact of different contexts on cued fear conditioning (Labar and Phelps 2005). These studies do not assess context conditioning, perhaps because of difficulties in measuring sustained affective responses with the traditional psychophysiological measures of conditioning such as the skin conductance. One advantage of startle is that it is an online probe that can track changes in emotional states. During conditioning, administration of startle stimuli in the presence and in the absence of a discrete CS provides a measure of cued and context conditioning, respectively. When context is defined by the spatial environment and is assessed with startle, context conditioning ensues. Thus, baseline startle is increased when subjects return to an aversive context where they have previously been conditioned with shocks (Grillon and Davis 1997).

As a model of anxiety, context conditioning should be influenced by the same factors known to affect anxious individuals. One such factor is predictability, which is a central theme in research on pathological anxiety (Foa et al. 1992). Anxious individuals have difficulty coping with temporally unpredictable aversive events (Craske et al. 1995). In animals, unpredictable stressors produce a wide range of durable negative emotional effects that are not produced by predictable stressors (Maier 1991; Mineka and Kihlstrom 1978; Overmier and Wielkewicz 1983). Empirical evidence in humans also shows that aversive stimuli tend to be more anxiogenic when they are unpredictable (Abbott and Badia 1979; Lejuez et al. 2000).

Predictability is inherent to conditioning - the process by which our environment becomes progressively more predictable - and is fundamental to context conditioning. Predictability determines the amount of conditioned fear/ anxiety that accrues to a discrete cue or to an aversive context. Conditioned fear develops to the stimulus or the situation that best predicts the aversive event. When a US is paired with the CS, the CS becomes the best predictor of the US and overshadows the context, resulting in little context conditioning (Rescorla and Wagner 1972). In contrast, with unpaired CS-US presentations, the US becomes unpredictable and the context becomes the only predictor, albeit a poor one, of the US, leading to increased context conditioning (Odling-Smee 1975a, b;
Rescorla and Wagner 1972). These results suggest that context conditioning should be greater after temporally unpredictable compared to predictable shocks in humans.

This hypothesis was confirmed in a study that examined conditioning during predictable (paired CS-US) or unpredictable (unpaired CS-US) shocks (Grillon and Davis 1997) over two sessions on separate days. A non-aversive conditioning task, in which the US was a signal for a reaction time, was also implemented as an experimental control. As expected, only the paired CS-US groups showed cued fear conditioning. However, context conditioning, measured as the increased baseline startle from the first to the second experimental session, was greater in the unpaired group compared to the paired group, which tended to show greater context conditioning compared to the control group (Fig. 1). Hence, consistent with the animal data, predictable shocks lead to substantial cued fear conditioning and little context conditioning, whereas unpredictable shocks result in robust context conditioning and no cued fear conditioning. These results demonstrate that startle, which is a reliable measure of cued fear conditioning (fear-potentiated startle), is also a dependent index of context conditioning.

Despite success in obtaining context conditioning in humans, context conditioning studies with spatial contexts are time consuming and difficult to implement due to the necessity to test subjects in different experimental rooms. As an alternative, computer-generated virtual reality (VR) environments can be used to create distinct spatial contexts while keeping the subjects stationary in the laboratory (Alvarez et al. 2007b; Baas et al. 2004a). Compared to standard conditioning experiments with isolated stimuli, VR provides a multitude of stimulating, complex, and engaging environments. VR is an ideal tool to study anxiety, as indexed by context conditioning, in within-subject designs. It provides data highly consistent with animal findings and with results from past context conditioning studies (Alvarez et al. 2007b; Grillon et al. 2006b). Grillon et al. (2006a, b) presented subjects with three virtual contexts, each being associated during acquisition with either no shock, predictable shocks (paired CS-US), or unpredictable shocks (unpaired CS-US) in a counterbalanced manner (Fig. 2). As expected, there was significant cued fear conditioning to the CS in the predictable condition only, as indicated by larger startle during the CS compared to intertrial intervals (ITI, absence of a CS). Startle during ITI in each virtual context, which provided an indicator of context conditioning, increased linearly from the no shock context, to the predictable, to the unpredictable context (Fig. 3; Grillon et al. 2006b). These results indicate that startle is a valuable measure of context conditioning in a discriminable conditioning procedure and further suggest that predictability is a crucial mitigating factor in context 


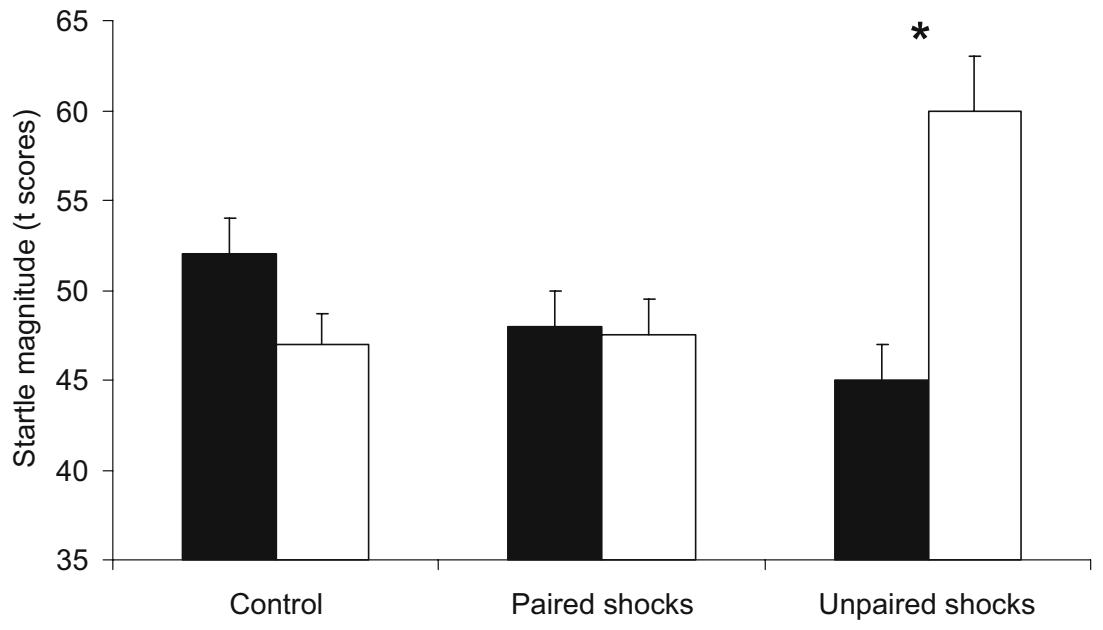

Session $1 \square$ Session 2

Fig. 1 Context conditioning after paired CS shock (predictable shocks), unpaired CS shock (unpredictable shocks), and non-aversive conditionings (control) in a between-group design. During nonaversive conditioning, the US was a signal for button-press. Subjects underwent conditioning in two experiment sessions separated by 4 5 days. Context conditioning was assessed by delivering startle stimuli at the beginning of sessions 1 and 2, before conditioning occurred. The figure shows that when subjects received unpaired CS-US, startle

conditioning. Behavioral studies in animals are consistent with these startle-based data in humans.

In animals, behavioral avoidance is a reliable measure of context conditioning (Bouton and King 1983). Given the choice between moving into a place where they previously received predictable and unpredictable shocks, rats will avoid the unpredictable context in favor of the predictable context (Odling-Smee 1975a, b). Human subjects show a similar behavioral avoidance of unpredictability. In the above virtual reality study, if subjects are left to navigate freely in the various context with a joystick to find magnitude was significantly larger when they return for testing (session 2) compared to before initial conditioning (session 1). In contrast, during the non-aversive condition, startle decreased (due to long-term habituation) between sessions 1 and 2. Startle magnitude in the paired CS-US condition was intermediated between these two conditions, suggesting weak context conditioning. Asterisk indicates a significant difference in startle magnitude between sessions 1 and 2 (adapted from Grillon and Davis 1997)

monetary reward, they will overwhelmingly choose the no shock context, but when left with the choice of the predictable and unpredictable contexts, a great majority of them $(80 \%)$ will choose the predictable context, consequently avoiding the unpredictable context (Grillon et al. 2006b).

As mentioned earlier, animal data show that the BNST is involved in context conditioning, but not in cued fear conditioning (Sullivan et al. 2004). Another structure that differentiates between cued and context conditioning is the hippocampus (Kim and Fanselow 1992; Pentkowski et al.

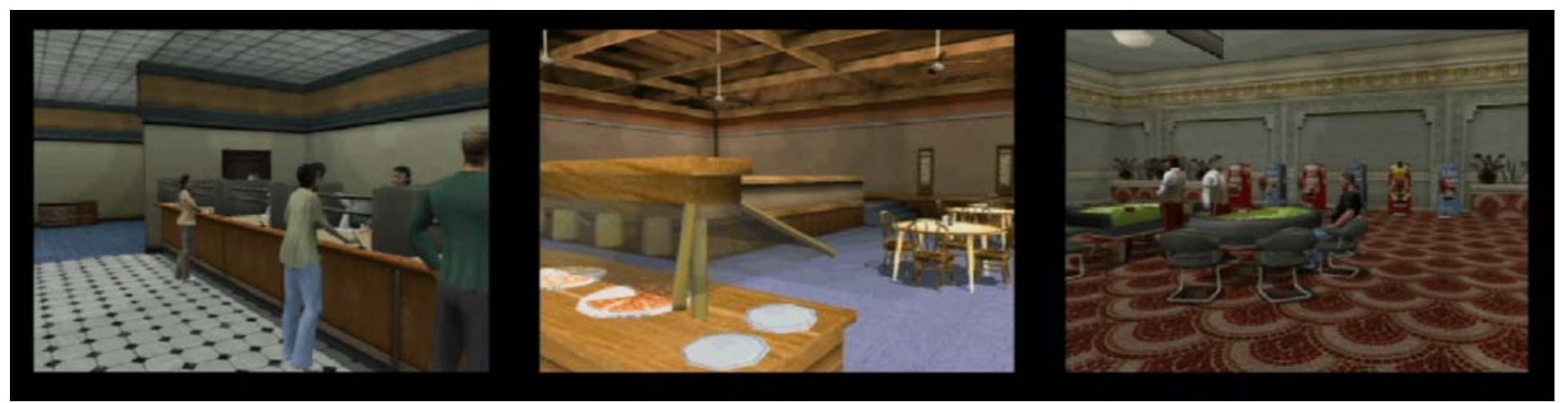

Fig. 2 Context conditioning using virtual reality. Subjects were presented with three virtual environments in which they underwent different types of aversive conditioning counterbalanced across contexts in a within-subject design. The three contexts were a casino, a bank, and a restaurant. Subjects were safe in the no-shock (N) context. They received paired CS shock in the predictable $(\mathrm{P})$ context and unpaired CS-shock in the unpredictable (U) context. An 8-s duration cue, a light, was presented in each context (not shown). The cue signaled the shock in the P context, but had no signal value in the $\mathrm{N}$ and $\mathrm{U}$ contexts (from Grillon et al. 2006b) 


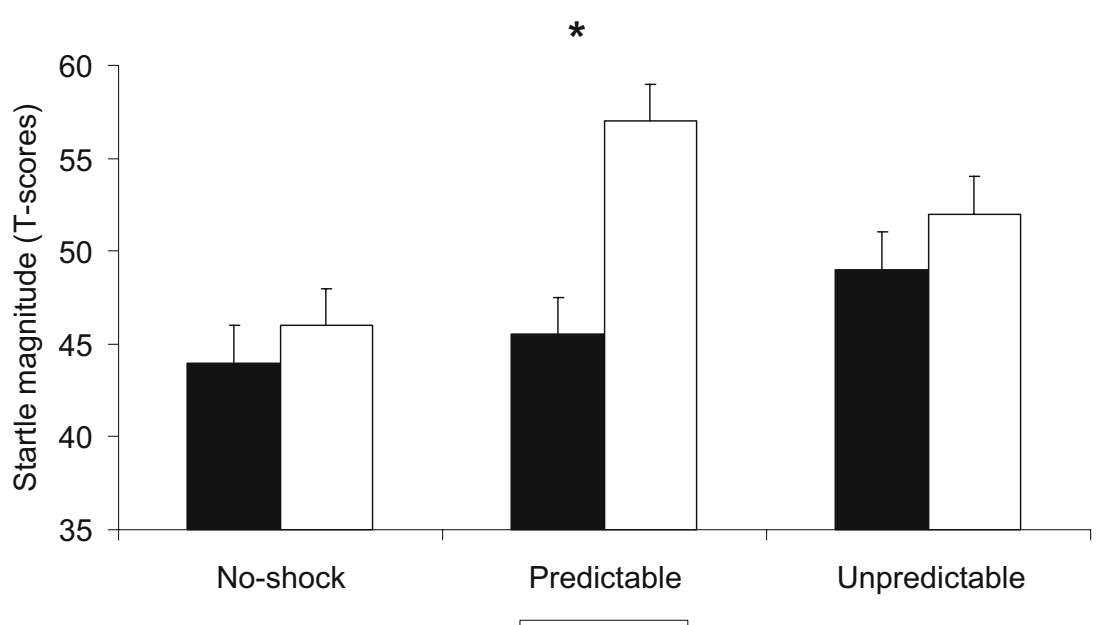

ITI $\square \mathrm{CS}$

Fig. 3 Magnitude of startle in each virtual context in the presence and in the absence of the CS (during intertrial interval or ITI). As expected, startle was significantly larger during the CS compared to ITI (fear-potentiated startle) only in the predictable condition, when the cue signaled the shock (two middle bars). Startle during ITI (black bars) is a measure of context conditioning, reflecting the degree of contextual anxiety associated with each context. Startle increased linearly from the control, to the predictable, to the unpredictable

2006; Phillips and LeDoux 1992; Richmond et al. 1999). That the hippocampus is involved in context conditioning is significant because this structure has been implicated in Gray's model of anxiety (Gray and McNaughton 2000). Gray also considers fear and anxiety as anatomically and functionally distinct phenomena. The flight/fight system underlies the activation of fear and is linked to the amygdala, whereas the Behavioral Inhibition System (BIS) mediates anxiety and is associated with the septohippocampal system. Thus, the BNST together with the BIS, may play a role in anxiety.

Not all studies find that lesions of the hippocampus affect context conditioning (Frankland et al. 1998; McNish et al. 1997; Winocur 1997). Recent preclinical evidence indicates that context conditioning is hippocampus-dependent for complex but not simple environments (Moses et al. 2007). This is consistent with human findings demonstrating that context conditioning with unidimensional contextual stimuli fails to activate the hippocampus (Armony and Dolan 2001), while more complex spatial environments do activate the hippocampus. We recently reported strong activation of the hippocampus during context conditioning to unpredictable shocks in a VR environment (Alvarez et al. 2007a). No activation of the BNST has been found, so far, in these context conditioning studies. Currently, the spatial resolution of imaging techniques may be too low to discriminate BNST from other surrounding structures with certainty, although a recent study reported BNST activation during anticipatory anxiety in specific phobics (Straube et al. 2007). contexts confirming that (1) context conditioning develops to environments associated with an aversive event and that (2) that context conditioning is affected by the predictability of the aversive event, unpredictable environments resulting in greater context conditioning compared to predictable environments. Asterisk indicates a significant increase in startle magnitude during the cue compared to ITI (adapted from Grillon et al. 2006b)

\section{Conditioning with long-duration CS}

Like context conditioning, long-duration CSs induce a sustained aversive state in rodents that can be blocked by lesions of the BNST (Waddell et al. 2006). Long-duration CSs have been rarely used in humans (Lovibond 1992). Lovibond (1992) argued that aversive conditioning with short-duration cues does not model anxiety for at least two reasons. First, short and transient aversive cues do not engage sustained aversive states that characterize anxiety. Second, the phasic skin conductance response is not a measure of an aversive state. Rather, it measures nonspecific orienting and anticipatory processes associated with the cue whether the cue signals an aversive or an innocuous stimulus. Lovibond further suggested that a better measure of conditioning with long-duration CS was the changes in tonic skin conductance. He went on to demonstrate robust differential conditioning with 10-40 s-duration CS's using tonic skin conductance levels and spontaneous fluctuations, with the former measure being more sensitive to differential conditioning than the second. So far, no startle studies in humans have used long-duration discrete CSs.

\section{Verbal instructions}

An alternative to conditioning is verbal instructions in which the time of US administration is verbally communicated rather than learned via experience (Grillon et al. 1991). Verbal instruction experiments mimic the mode of communication of danger typically involved in everyday 
human life without directly experiencing the aversive event (e.g., one learns to fear an electrical outlet, not because one has been electrocuted, but because one has been forewarned of the risk). One advantage of the verbal instructions procedure over aversive conditioning is that it eliminates interindividual variability in associative learning as a potential confound.

Similar to conditioning experiments, shocks can be administered in a predictable and unpredictable manner to elicit fear and anxiety, respectively. Subjects informed that they can receive shocks show sustained enhancement of startle reactivity compared to a safe condition without risk of shock. This startle enhancement is greater when shocks are administered unpredictably compared to predictably (Fig. 4 top; Grillon et al. 2004). Furthermore, there is a large phasic potentiation of startle during the cue that signals the shocks in the predictable condition. Impor- tantly, not all aversive stimuli generate a sustained startle potentiation mitigated by predictability. Intense airpuffs directed to the neck at the level of the larynx have been used as aversive stimuli (Grillon et al. 2004). These stimuli generate reliable startle potentiation to a threat cue, but do not generate sustained contextual anxiety when administered unpredictably (Fig. 4 bottom), suggesting that unpredictability per se is not anxiogenic (Staub et al. 1971). Unpredictability is a significant aspect of emotional reactivity to danger only for stimuli that are sufficiently noxious or unpleasant (Mineka and Kihlstrom 1978).

\section{Darkness}

Like in rats, startle in humans is also affected by changes in background illumination. When human subjects receive acoustic startle stimuli in a dark environment, their startle
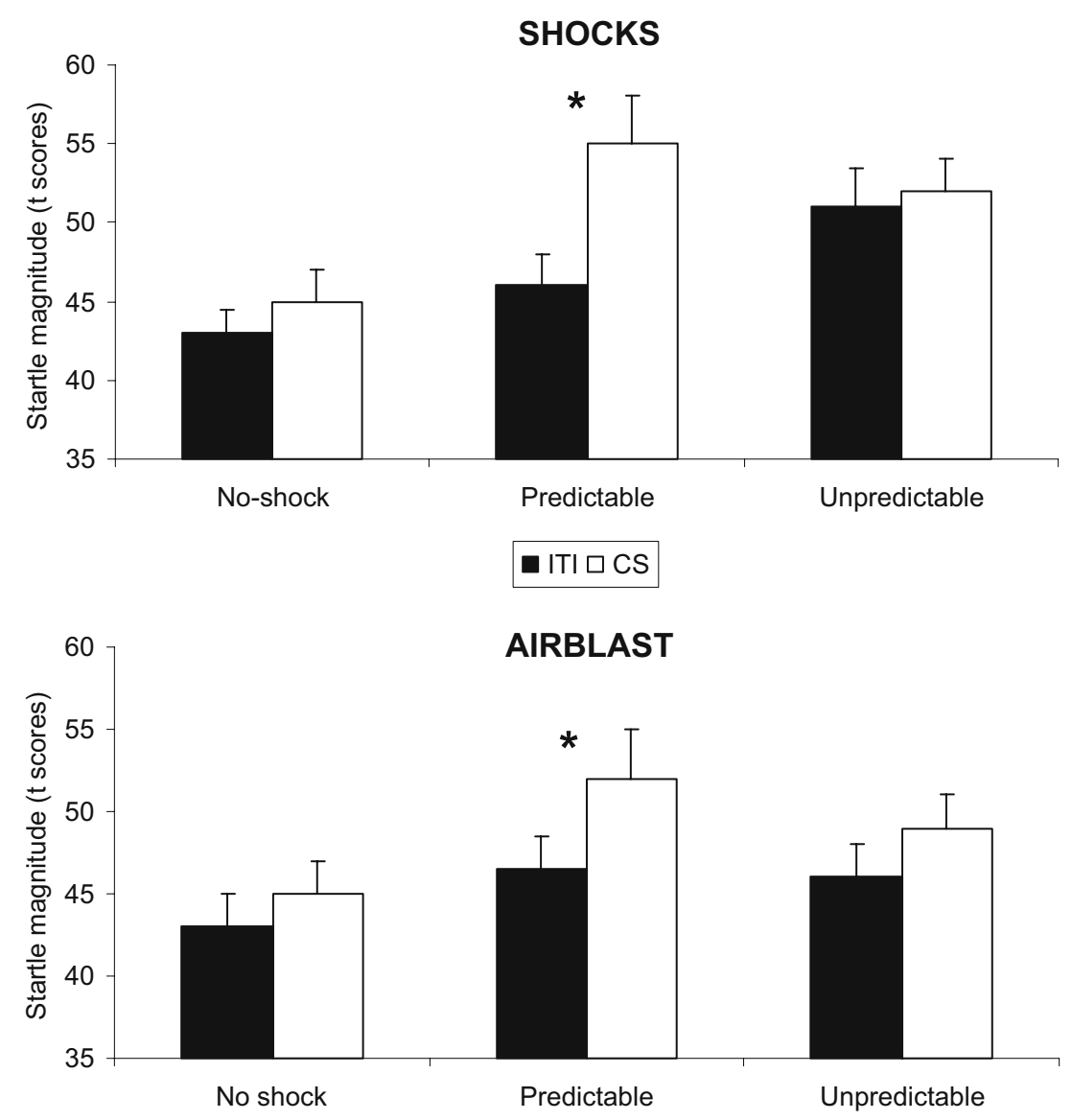

Fig. 4 Verbal instructions experiment. Subjects were verbally instructed that they would be safe in the no-shock $(\mathrm{N})$ condition and that they would receive aversive stimuli signaled by a threat cue in the predictable $(\mathrm{P})$ condition and unsignaled aversive stimuli in the unpredictable (U) condition. An 8-s duration cue was presented in each context. The cue signaled the aversive stimulus in the P context, but had no signal value in the $\mathrm{N}$ and $\mathrm{U}$ contexts. Two types of aversive stimuli were used in a between-group design, a shock, and a blast of air directed
ITI $\square$ CS

to the throat at the level of the larynx. The results of the shock group are very similar to results in the context conditioning shown in Fig. 3. In the predictable condition, startle was larger during the CS compared to ITI (fear-potentiated startle). In addition, startle during ITI (black bars) increased linearly from the control, to the $\mathrm{P}$, to the $\mathrm{U}$ condition. However, such a pattern of response was not seen in the airblast group. Asterisk indicates a significant increased in startle magnitude during the cue compared to ITI (adapted from Grillon et al. 2004) 
responses are increased compared to an illuminated environment (Grillon et al. 1997b). The 'darkness-facilitation of startle" in humans is a relatively weak, but replicable, effect. It has been demonstrated in adolescents (Grillon et al. 1999) and in adults (Grillon and Ameli 1998; Grillon et al. 1997b, 1998b), showing a high consistency of results across three laboratories(Grillon et al. 1999). It is likely that the facilitation of startle in the dark in humans, a diurnal species, is equivalent to the light-enhanced startle in rodents (Walker and Davis 1997b), a nocturnal species (Grillon et al. 1997b). That the "darkness-facilitation of startle" reflects an aversive state is suggested by the fact that the magnitude of the effect correlates with retrospective ratings of fear of the dark as children (Grillon et al. 1997b), is increased in individuals with PTSD (Grillon et al. 1998b) and is blocked by the benzodiazepine diazepam (Baas et al. 2002). Alternatively, the darkness-facilitation of startle could be caused by an attentional effect. According to this view, deprivation of visual information would lead to enhanced processing of auditory stimuli, which is known to increase acoustic startle (Filion et al. 1993; Hackley and Graham 1987). To test this possibility, the effect of darkness on prepulse inhibition (PPI) of startle was investigated (Grillon et al. 1997b). Prepulse inhibition of startle is the inhibition of startle by a weak prestimulus presented shortly before the startle-eliciting stimulus. Because PPI is increased by attention to the prepulse (Jennings et al. 1996), an acoustic prepulse should increase PPI if darkness increases the processing of auditory information. However, darkness was not found to increase PPI. The PPI findings are inconsistent with an attentional interpretation of the facilitation of startle in the dark.

Empirical studies of sustained anxiety:

psychopharmacological and clinical validity

\section{Psychopharmacology}

There is mounting empirical evidence of the relevance of sustained anxiety in aversive contexts, as opposed to cued fear, to clinical anxiety. If sustained anxiety is a good model for anxiety disorders, one would expect that drugs that alleviate anxiety also reduce sustained anxiety. In fact, evidence shows that the benzodiazepine alprazolam, does not affect fear-potentiated startle to an explicit threat cue, but reduces the potentiation of startle to aversive shock contexts (Baas et al. 2002; Grillon et al. 2006a). Baas et al. (2002) conducted four separate studies using withinsubjects and between-groups designs with two types of benzodiazepines, diazepam and oxazepam. In none of the studies did benzodiazepine reduced significantly fearpotentiated startle to a short duration threat cue. These results have been confirmed by some (Riba et al. 1999;
Scaife et al. 2005), but not others (Bitsios et al. 1999; Riba et al. 2001; see Grillon and Baas 2002; Walker and Davis $2002 \mathrm{~b}$ for a discussion of issues related to the effect of benzodiazepines on fear-potentiated startle). Recently, we replicated the lack of effect of benzodiazepines on fearpotentiated startle to a threat cue using alprazolam (Grillon et al. 2006a). However, we found that alprazolam reduced substantially and significantly the sustained potentiation of startle to aversive contexts (Grillon et al. 2006a) (Fig. 5).

These results are somewhat inconsistent with startle studies in rodents showing that benzodiazepines block fearpotentiated startle to a discrete conditioned cue (Davis et al. 1993). Because benzodiazepines impair learning and memory, it is possible that these drugs interfere with learning or consolidation processes when the drug is administered before conditioning or with recollection of cued fear conditioning when administered before testing rather than with the expression of fear (Harris and Westbrook 2001). However, it is most likely that the discrepancies between rodent and human studies are due to the large difference in doses used in the two species. Indeed, perhaps because rodents are less susceptible to the sedative effects of benzodiazepines compared to humans, studies have typically used much higher doses in rodents $(0.25-2 \mathrm{mg} / \mathrm{kg}$ intraperitoneally) than in humans $(0.1-0.5 \mathrm{mg} / \mathrm{kg}$ orally). At higher doses, benzodiazepines may have effects in animals that are not relevant to their clinical efficacy. That benzodiazepines affect preferentially sustained anxiety compared to phasic fear is supported by two set of data. Ethological studies show greater efficacy of benzodiazepines on risk assessment behaviors (anxiety) compared to unconditioned fear to proximal threat (fear; Blanchard et al. 2003). In addition, in humans the benzodiazepine diazepam prevents the acquisition but not the expression of fear-potentiated startle to a conditioned threat cue (Scaife et al. 2005).

\section{Clinical anxiety}

So far, there has not been any systematic investigation of sustained anxiety in startle studies in anxiety disorders using controlled experiments. In the only context conditioning study conducted so far, Vietnam veterans with PTSD showed enhanced context conditioning when returning to an experimental room where they had previously received shocks (Fig. 6; Grillon and Morgan 1999).

Despite the relative absence of specific research on this issue, indirect evidence for enhanced sustained anxiety in individuals with anxiety disorders is abundant. There are numerous reports of increased physiological arousal or subjective anxiety in anxious patients during conditions of distal threat, for example, during the period that precedes a future psychological or chemical challenges (Alpers et al. 2003; Braune et al. 1994; Charney et al. 1984; Coplan et al. 


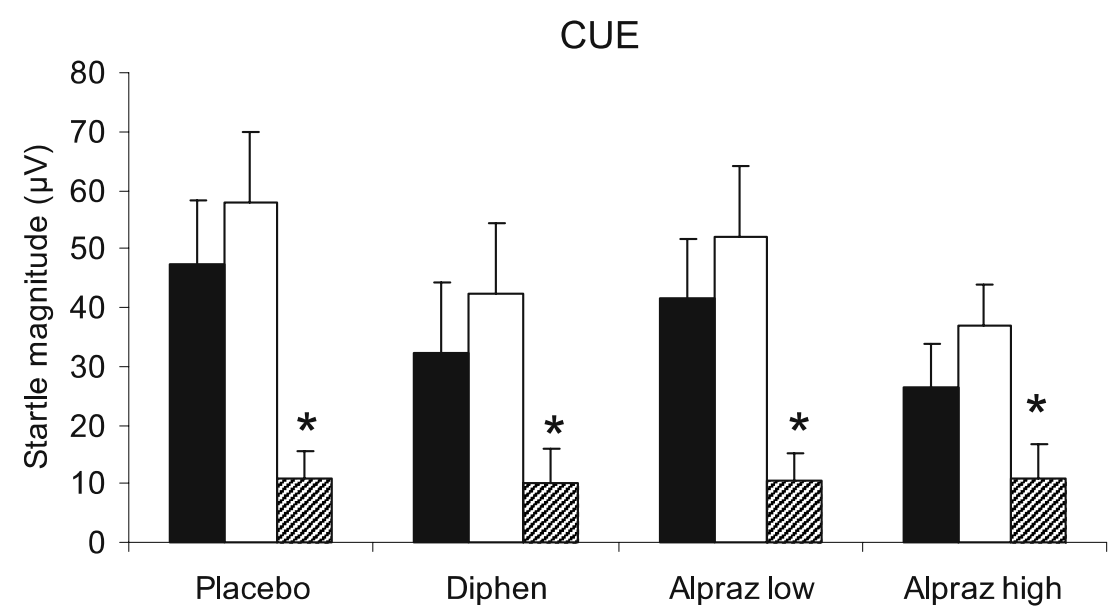

ITI $\square$ Threat $\mathbb{Q}$ Difference scores

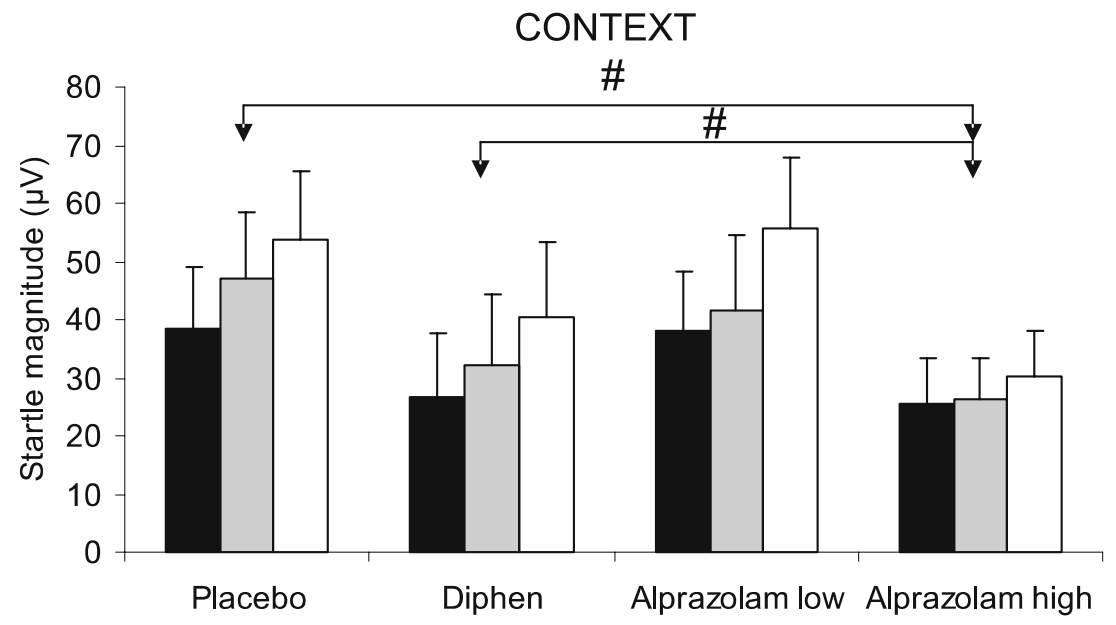

No shock $\square$ Predictable $\square$ Unpredictable

Fig. 5 Effect of the benzodiazepine alprazolam on verbally mediated cued fear and contextual anxiety. The paradigm was the same as presented in Fig. 4. Subjects were informed that there would be three conditions, (1) no shock (N), (2) predictable (P) shocks, and unpredictable $(\mathrm{U})$ shocks. Each subject received placebo, $0.5 \mathrm{mg}$ of alprazolam, $1 \mathrm{mg}$ of alprazolam, or $50 \mathrm{mg}$ of diphenhydramine (Benadryl). Diphenhydramine was used as an active control to match the sedative properties of alprazolam on startle. Top: startle magnitude during the cue and ITI in the P condition in the P conditions only. The difference scores between cue and ITI is a measure of fear-potentiated startle. Alprazolam did not affect fear-potentiated startle. Bottom: startle during ITI (contextual anxiety) in the $\mathrm{N}, \mathrm{P}$, and U condition. As

1998; Hoehn et al. 1997; Parente et al. 2005). Similarly, mere participation in an experiment involving the future delivery of aversive stimuli can generate substantial anticipatory anxiety that can be measured with the startle reflex (Bocker et al. 2004; Grillon and Ameli 1998). Anxious patients are particularly vulnerable to this type of contextual anxiety. Baseline startle, but not fear-potentiated startle to a threat cue, is increased in individuals with PTSD or panic disorder compared to controls in anticipation of in Figs. 3 and 4, startle increased linearly from the $\mathrm{N}$ to the $\mathrm{P}$ to the $\mathrm{U}$ condition with placebo. This effect was replicated with the low dose of alprazolam and with diphenhydramine. However, there was a significant reduction of startle with the high dose of alprazolam, indicating substantial reduction in contextual anxiety. This effect was not caused by sedation because diphenhydramine, which reduced baseline startle to the same extent as $1 \mathrm{mg}$ alprazolam, did not affect contextual anxiety. Asterisk indicates a significant increased in startle magnitude during the cue compared to ITI. Number sign indicates a significant Condition $\times$ Drug linear trend between conditions (adapted from Grillon et al. 2006a)

future shocks (Grillon et al. 1994, 1998c; Morgan III et al. $1995 \mathrm{a}, \mathrm{b})$. This exaggerated startle reaction is contextspecific; it is not found in these patients when tested in a safe context (Grillon et al. 1998c; Ludewig et al. 2002). Similarly, an association between PTSD symptoms severity in urban police officers and the level of contextual threat in a threat of shock experiment has been documented (Pole et al. 2003). Symptom severity is strongly associated with startle magnitude under a low contextual threat condition, 


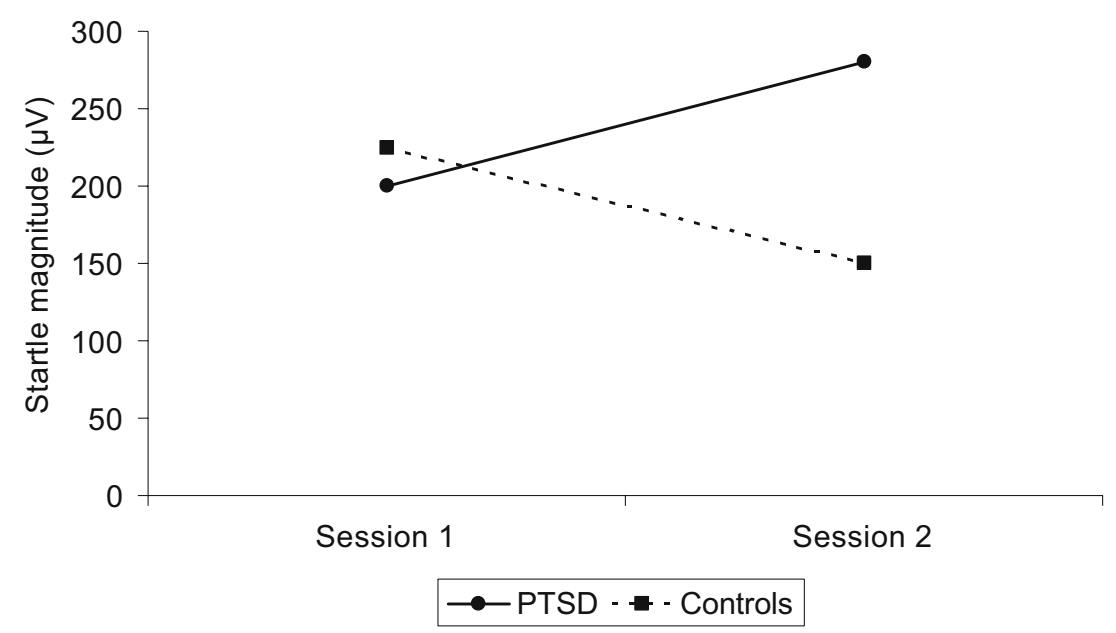

Fig. 6 Context conditioning in Vietnam veterans with PTSD. Subject underwent differential aversive conditioning in which one cue was paired with a shock (CS+), and the other was not (CS-) over two experimental sessions separated by a week. Context conditioning was assessed by delivering startle stimuli at the beginning of each session, before conditioning occurred. The figure shows significant context

when the shock electrodes are not attached and the threat is remote, but not under a high threat condition, when electrodes are attached and there is an actual risk of receiving a shock. These results point to a vulnerability of anxious patients to uncertain or distal threat rather than to certain and imminent danger.

Also consistent with the above results are findings from emotional imagery procedures during which texts describing neutral, disorder-specific personal fearful, and nonspecific fearful situations are used as prompts to an imagined and personal experience of events. Under these conditions, unlike patients with phobias, patients with panic disorder or PTSD do not show increased fear-potentiated startle to their own disorder-specific scenes, but they show elevated baseline startle (Cuthbert et al. 2003). According to the authors, this enhanced baseline startle may reflect anxiety to the experimental context (Lang et al. 1998, 2000).

We have obtained preliminary evidence of increased sustained anxiety in anxiety disorders using our instructed fear learning experiment (Lissek et al. 2005). While individuals with panic disorder or with posttraumatic stress disorder showed normal fear-potentiated startle to the shortduration threat cue, they exhibited increased sustained potentiated startle to the shock contexts. However, sustained anticipatory anxiety appears to be a feature that cut across anxiety disorders and is not restricted to panic disorder and posttraumatic stress disorder. Enhancement anticipatory anxiety has been reported in speech-fearful individuals, as evidenced by elevated baseline startle before delivery of a speech (Cornwell et al. 2006). In these individuals, startle magnitude, but not the skin conductance or heart rate, correlates with their fear of negative evaluation, a core component of social anxiety, but conditioning in the PTSD (startle magnitude increased from session 1 to session 2) but not in the control group (startle magnitude habituated between session 1 and 2). This pattern of startle modulation resulted in a significant Group $\times$ Session interaction (adapted from Grillon and Morgan 1999)

not with Spielberger's trait anxiety, a more general measure of anxiety (Cornwell et al. 2006). Interestingly, a recent study reported activation of the BNST in phobic subjects during anticipation of their phobogenic stimulus (Straube et al. 2007).

\section{Risks for anxiety}

Collectively, these results suggest that context-specific startle potentiation may be an endophenotype of anxiety disorders. This is supported by the finding that non-affected children of parents with mood and anxiety disorders also exhibit enhanced anticipatory anxiety in threatening contexts using startle (Grillon et al. 1997a, 1998a, 2005; Pine et al. 2005) or the skin conductance as measures of anxiety (Turner et al. 2005). However, this conclusion is based on indirect evidence. Studies are underway to demonstrate that enhanced sustained experimental anxiety is a characteristic of anxious patients and potentially a vulnerability marker for anxiety disorders using controlled experiments in which fear and anxiety responses can be assessed.

In addition to vulnerability conferred by parental history of anxiety disorders, risks for anxiety disorders include prior stress and being a woman. The impact of stress on the development of mood and anxiety disorders is well documented (Millon and Davis 1999; Young et al. 1997). Similarly, there is substantial data pointing to a greater incidence of mood and anxiety disorders in women compared to men (Kessler et al. 1994). These two risk factors have now been linked to contextual anxiety (Grillon, submitted for publication; Grillon et al. 2007). Exposure to a stressor increases subsequent contextual anxiety, as measured with the darkness-facilitation of startle 
test (Grillon et al. 2007). With regard to sex differences, using the same threat experiment presented in Fig. 4, we recently found that men and women did not differ in their fear-potentiated startle to a threat cue but that women showed enhanced sustained anxiety to the aversive contexts (Grillon, submitted for publication). These results are consistent with the conclusions of a review of sex difference in fear and anxiety in rats in experimental models of anxiety based on startle (Toufexis 2007). Toufexis (2007) argued that female and male rats did not differ in fearpotentiated startle to a discrete conditioned cue, but that female rats showed greater reactivity in models of sustained anxiety. The authors related these findings to sexual dimorphism in the BNST (Allen and Gorski 1990) and to action of sex hormones on these structures (Toufexis 2007). One should be cautious, however, in readily attributing sex difference in anxiety uniquely to sex hormones. It is likely that psychosocial factors, such as maternal behaviors (Moore and Morelli 1979; Reid 1994) and cognitive appraisal processes (Cole and Sapp 1988; Mak et al. 2004), are also involved in these sex effects.

\section{A working hypothesis: role of glucocorticoids in anxiety}

Anxiety is an adaptive response to uncertain threat, but it becomes pathological when it is disproportionate to the threat, persists beyond the presentation of the stressor, or is triggered by innocuous stimuli or situations. What potential mechanisms may promote pathological anxiety? Overexpression of CRH activity in the BNST by glucocorticoids may be one such mechanism. Other neurotransmitters, such as serotonin and noradrenalin, are also likely to be involved in anxiety disorders, but we focus here on the relationship between cortisol and CRH because of the wealth of data on CRH modulation of startle.

Glucocorticoids do not affect emotional behavior per se but induce chemical changes in particular brain structures, making the occurrence of certain behaviors more likely in certain contexts (Korte 2001). In rodents, corticosterone (the principal glucocorticoid in rats) has well-known inhibitory effects on subsequent release of HPA-axis CRH, but it also has excitatory effects on CRH at extra-hypothalamic sites (Swanson and Simmons 1989), including the BNST (Makino et al. 1994b). Corticosterone upregulates CRH mRNA transcription in the BNST, even though it decreases mRNA in the medial paraventricular nucleus of the hypothalamus, where neuronal elements secreting $\mathrm{CRH}$ into the neurohypophysial-portal system are localized (Makino et al. 1994b). Exposure to a predator odor elevates plasma levels of corticosterone and adrenocorticotropic hormone $(\mathrm{ACTH})$ and stimulates c-fos mRNA expression in the BNST (Masini et al. 2005). It has been suggested that glucocorticoids can potentiate anxiety via feed-forward regulation of $\mathrm{CRH}$ by glucocorticoids in limbic structures, including the BNST (Schulkin et al. 2005). This possibility is consistent with the observation that chronic injection of corticosterone potentiates startle responses to sub-effective doses of CRH (Lee et al. 1994) and treatments that block the synthesis of glucocorticoids alleviate anxiety. Thus, administration of a steroid synthesis inhibitor reduces both the sustained anxiety in rats exposed to cat odors (Cohen et al. 2000) and the stress-induced anxiogenic-like behavior on the elevated plus-maze (Calvo et al. 1998).

Could glucocorticoids be similarly involved in humans? The role of glucocorticoids in responses to stressful events is well-known and prolonged glucocorticoid release has been linked to pathological anxiety. Data indicate a positive correlation between anxiety and cortisol (Berger 1980; Levitt et al. 1963; Sachar 1970). Increases in circulating cortisol in pathological states such as Cushing's disease, depression, or other psychiatric disorders, are often associated with a state of anxiety (Warburton 1974). Glucocorticoids are also involved in a number of procedures that generate anxiety as opposed to fear. For instance, cortisol and anticipatory anxiety are elevated before sodium lactate infusion among the patients who eventually develop a panic attack after infusion, compared to patients who do not panic and healthy controls (Coplan et al. 1998). Furthermore, panic attacks themselves do not lead to increased cortisol levels (Hollander et al. 1989; Liebowitz et al. 1985; Woods et al. 1987). In driving phobics, cortisol levels are elevated $1 \mathrm{~h}$ before driving exposure, without further increase during an actual driving test (Alpers et al. 2003).

That cortisol sensitizes anxiety due to its effect on extrahypothalamic CRH is a testable hypothesis. Stressful procedures that elicit cortisol release or exogenous cortisol should enhance anxiety. Consistent with this, we recently found that the darkness-facilitation of startle was enhanced in humans after exposure to a speech stressor, which is known to increase cortisol levels (Grillon et al. 2007). On the other hand, glucocorticoid receptor antagonists such as metyrapone should reduce anxiety. There is currently no such study using the startle reflex, but there is preliminary evidence from another source. Belgorodsky et al. (2005) examined the effect of metyrapone on anticipatory anxiety to a panicogenic challenge in individuals with panic disorders. They showed that metyrapone reduces cortisol levels by $30 \%$ and increases ACTH levels more than tenfold. It is likely that hypothalamic CRH levels (which were not measured) also increased substantially due to the lack of inhibitory feedback from cortisol. If anxiety was associated with hypothalamic CRH, an increase in anxiety would have been expected. Instead, metyrapone was found to decrease anxiety, without affecting fear to the challenge itself (Belgorodsky et al. 2005). Taken together, these results are in line with the hypothesis that the link between 
cortisol and extra-hypothalamic CRH may be involved in pathological anxiety.

\section{Conclusion and future directions}

Progress in understanding the pathogenesis of anxiety and in developing better treatments is critically dependent on identifying the components of anxiety disorders that differentiate controls from patients and that can be targeted for drug development. This approach is highly contingent on our ability to develop relevant models of anxiety. In this regard, animal models have proven to be crucial as most of our knowledge of the neurobiology and psychopharmacology of anxiety-related states have come from preclinical studies in animals. Growing empirical evidence points to a behavioral, anatomical, and functional distinction between phasic and sustained aversive states to temporally certain and uncertain threat, respectively. The preclinical literature indicates that separate but interacting limbic structures underlie these two responses. Results mostly based on startle studies show that the CeA, which mediates fear, is activated by discrete cues that signal an aversive event and promote a behavioral response of fight or flight. The BNST is activated by more temporally uncertain (Walker et al. 2003) or distal (Waddell et al. 2006) threats. This structure is required to maintain the sustained state of anxiety that ensues.

Studies based on the startle reflex points to a similar distinction in humans and further suggest that mechanisms underlying anxiety as opposed to fear, are particularly relevant to anxiety disorders. Progress in our comprehension of anxiety and its dysfunction will depend on our ability to model sustained aversive states in the laboratory to better characterize their functional role and uncover their neurobiological and psychopharmacological underpinning. Research in this area in humans is still at an immature stage and in need of additional development. The great majority of experimental models rely on responses to a discrete threat cue. Future studies should focus on models of sustained anxiety in humans and examine their clinical and psychopharmacological relevance. Current studies suggest that the strongest rationale to study experimental models of anxiety is in panic disorder, PTSD, generalized anxiety disorder. It will be informative to contrast these disorders to the phobic or 'fear' disorders. Also of interest is to examine whether anxiolytics currently used to treat anxious patients are similarly effective in experimental models of anxiety. A related area of interest will be to examine whether experimental models of anxiety, as opposed to fear, have predictive validity for novel anxiolytic compounds. Currently, the predictive validity of animal models is quite poor (Rodgers 1997), perhaps because the nature of aversive states, these models mimic, is not clear. Testing candidate anxiolytics with similar models of anxiety in animals and humans may increase the predictive validity of experimental models, and ultimately may lead to better psychopharmacological treatment.

Finally, a key to a better comprehension of phasic and sustained aversive states will be to determine the time when the transition between amygdala-mediated and BNSTmediated responses occurs after threat onset. In other words, it is important to delineate the time course of amygdala and BNST involvement and define precisely the duration of 'short-' and 'long-'duration threat periods. There is currently no clear response to this question, in part, because very few studies have compared the influence of the amygdala and of the BNST on short- and longduration threat. The BNST is clearly involved in the effect of stressors that last several minute (Sullivan et al. 2004; Waddell et al. 2006; Walker and Davis 1997a) to hours or days (Bangasser et al. 2005; Hammack et al. 2004). The earliest time of BNST involvement is unknown. As already indicated, the BNST is not involved in the expression of fear-potentiated startle to CS lasting $3.7 \mathrm{~s}$ (Campeau and Davis 1995; Hitchcock and Davis 1986; Sananes and Davis 1992). It is also not required for freezing to a 20-s discrete cue, but it is necessary for freezing to context (Sullivan et al. 2004). Furthermore, BNST lesions do not affect conditioned suppression of bar-pressing behavior to a 1-min discrete CS but greatly reduces conditioned suppression to a 10-min discrete CS (Waddell et al. 2006). However, because in this study BNST lesions were made before training, it is unclear whether BNST lesions disrupt conditioned fear learning or conditioned fear expression. Distinguishing the role of the BNST in the acquisition vs expression of conditioned fear should also be the focus of future studies.

Because animals can be conditioned with long-duration CSs (including discrete or contextual CS), lesions of the amygdala and BNST should provide clues as to the contribution of these structures to changes in aversive states over time. Startle studies are ideally suited for such an experiment because startle can be used as a probe to track ongoing affective states. By delivering startle stimuli at an appropriate time after CS onset, one should be able to establish the respective time course of amygdala and BNST involvement in fear and anxiety. One would expect lesions of the amygdala to block potentiated startle during the early phase but during the late phase of a long-duration CS's, the reverse being true for the BNST. Similarly, in humans, one may be able to use startle in combination with anxiolytic treatments that reduce one or the other response (e.g., benzodiazepines which affect sustained but not phasic states) to determine the duration of each state. Based on our findings (Grillon et al. 2006a), one would expect 
alprazolam to reduce fear-potentiated startle to a longduration threat stimulus in the late but not early phase of a long-duration threat cue or context.

Acknowledgment This research was supported by the Intramural Research Program of the National Institutes of Mental Health. Dr. Grillon reports no competing interests.

\section{References}

Abbott B, Badia P (1979) Choice for signaled over unsignaled shock as a function of signal length. J Exp Anal Behav 32:409-417

Adamec RE, McKay D (1993) Amygdala kindling, anxiety, and corticotrophin releasing factor (CRF). Physiol Behav 54:423-431

Alheid GF, Beltramino CA, De Olmos JS, Forbes MS, Swanson DJ, Heimer L (1998) The neuronal organization of the supracapsular part of the stria terminalis in the rat: the dorsal component of the extended amygdala. Neuroscience 84:967-996

Allen LS, Gorski RA (1990) Sex difference in the bed nucleus of the stria terminalis of the human brain. J Comp Neurol 302:697-706

Alpers GW, Abelson JL, Wilhelm FH, Roth WT (2003) Salivary cortisol response during exposure treatment in driving phobics. Psychosom Med 65:679-687

Alvarez E, Lissek S, Biggs A, Grillon C (2007a) Contextual fear conditioning in a virtual reality environment: a fMRI study The Organization for Human Brain Mapping, Chicago, Il

Alvarez RP, Johnson L, Grillon C (2007b) Contextual-specificity of short-delay extinction in humans: renewal of fear-potentiated startle in a virtual environment. Learn Mem 14:247-253

American Psychiatric Association (1994) Diagnostic and statistical manual of mental disorders, 4th edn. American Psychiatric Association, American Psychiatric Association

Armony JL, Dolan RJ (2001) Modulation of auditory neural responses by a visual context in human fear conditioning. Neuroreport 12:3407-3411

Baas JM, Grillon C, Bocker KB, Brack AA, Morgan CA 3rd, Kenemans JL, Verbaten MN (2002) Benzodiazepines have no effect on fear-potentiated startle in humans. Psychopharmacology (Berl) 161:233-247 Epub 2002 Mar 20

Baas JM, Nugent M, Lissek S, Pine DS, Grillon C (2004a) Fear conditioning in virtual reality contexts: a new tool for the study of anxiety. Biol Psychiatry 55:1056-1060

Baas JMP, Milstein J, Donlevy M, C G (2004b) Effects of anticipation of shock on brainstem auditory evoked potentials 3rd Dutch Endo-Neuro-Psycho Meeting, Doorwerth, The Netherlands

Bangasser DA, Santollo J, Shors TJ (2005) The bed nucleus of the stria terminalis is critically involved in enhancing associative learning after stressful experience. Behav Neurosci 119: $1459-1466$

Barlow DH (2000) Unraveling the mysteries of anxiety and its disorders from the perspective of emotion theory. Am Psychol 55:1247-1263

Barlow DH, Di Nardo PA (1991) The diagnosis of generalized anxiety disorder. Development, current status, and future directions. In: Rapee RM, Barlwo DH (eds) Chronic anxiety: generalized anxiety disorder and mixed anxiety-depression. Guilford, New York, pp 95-118

Belgorodsky A, Knyazhansky L, Loewenthal U, Arbelle J, Cohen H, Benjamin J (2005) Effects of the cortisol synthesis inhibitor metyrapone on the response to carbon dioxide challenge in panic disorder. Depress Anxiety 21:143-148

Berger FM (1980) Effect of antianxiety drugs on fear and stress. Behav Sci 25:315-321
Bitsios P, Philpott A, Langley RW, Bradshaw CM, Szabadi E (1999) Comparison of the effects of diazepam on the fearpotentiated startle reflex and the fear-inhibited light reflex in man. J Psychopharmacol 13:226-234

Blanchard RJ, Yudko EB, Rodgers RJ, Blanchard DC (1993) Defense system psychopharmacology: an ethological approach to the pharmacology of fear and anxiety. Behav Brain Res 58:155-165

Blanchard DC, Griebel G, Blanchard RJ (2003) The mouse defense test battery: pharmacological and behavioral assays for anxiety and panic. Eur J Pharmacol 463:97-116

Bocker KB, Baas JM, Kenemans JL, Verbaten MN (2004) Differences in startle modulation during instructed threat and selective attention. Biol Psychol 67:343-358

Bolles RC, Fanselow MS (1980) A perceptual-defense-recuperative model of fear and pain. Behav Brain Sci 3:291-323

Bouton ME, King DA (1983) Contextual control of the extinction of conditioned fear: tests for the associative value of the context. J Exp Psychol Anim Behav Processes 9:248-265

Bouton ME, Mineka S, Barlow DH (2001) A modern learning theory perspective on the etiology of panic disorder. Psychol Rev $108: 4-32$

Braune SS, Albus MM, Fröhler MM, Höhn TT, Scheibe GG (1994) Psychophysiological and biochemical changes in patients with panic attacks in a defined situational arousal. Eur Arch Psychiatry Clin Neurosci 244:86-92

Brown TA, Chorpita BF, Barlow DH (1998) Structural relationships among dimensions of the DSM-IV anxiety and mood disorders and dimensions of negative affect, positive affect, and autonomic arousal. J Abnorm Psychol 107:179-192

Butler RW, Braff DL, Rausch JL, Jenkins MA, Sprock J, Geyer MA (1990) Physiological evidence of exaggerated startle response in a subgroup of Vietnam Veterans with combat-related PTSD. Am J Psychiatr 147:1308-1312

Calvo N, Martijena ID, Molina VA, Volosin M (1998) Metyrapone pretreatment prevents the behavioral and neurochemical sequelae induced by stress. Brain Res 800:227-235

Campeau S, Davis M (1995) Involvement of the central nucleus and basolateral complex of the amygdala in fear conditioning measured with fear-potentiated startle in rats trained concurrently with auditory and visual conditioned stimuli. J Neurosci 15: 2301-2311

Carlsson K, Andersson J, Petrovic P, Petersson KM, Ohman A, Ingvar M (2006) Predictability modulates the affective and sensorydiscriminative neural processing of pain. NeuroImage 32:1804 1814

Carroll BJ, Curtis GC, Mendels J (1976) Cerebrospinal fluid and plasma free cortisol concentrations in depression. Psychol Med 6:235-244

Charney DS, Heninger GH, Breier A (1984) Noradrenergic function in panic anxiety: effects of yohimbine in healthy subjects and patients with agoraphobia and panic disorder. Arch Gen Psychiatry 41:751-763

Cohen HH, Benjamin JJ, Kaplan ZZ, Kotler MM (2000) Administration of high-dose ketoconazole, an inhibitor of steroid synthesis, prevents posttraumatic anxiety in an animal model. Eur Neuropsychopharmacol 10:429-435

Cole T Jr, Sapp GL (1988) Stress, locus of control, and achievement of high school seniors. Psychol Rep 63:355-359

Coplan JD, Goetz R, Klein DF, Papp LA, Fyer AJ, Liebowitz MR, Davies SO, Gorman JM (1998) Plasma cortisol concentrations preceding lactate-induced panic. Psychological, biochemical, and physiological correlates. Arch Gen Psychiatry 55:130-136

Cornwell BR, Johnson L, Berardi L, Grillon C (2006) Anticipation of public speaking in virtual reality reveals a relationship between trait social anxiety and startle reactivity. Biol Psychiatry 59:664-666 
Cornwell BR, Baas JMP, Johnson L, Holroyd T, Carver FW, Lissek S, Grillon C (2007) Neural responses to auditory stimulus deviance under threat of electric shock revealed by spatially-filtered magnetoencephalography. Neuroimage 37:282-289

Craske MG, Glover D, DeCola J (1995) Predicted versus unpredicted panic attacks: acute versus general distress. J Abnorm Psychology 104:214-223

Cuthbert BN, Lang JL, Strauss C, Drobes D, Patrick CJ, Bradley MB (2003) The psychophysiology of anxiety disorders: fear memory imagery. Psychophysiology 40:407-422

Davis M, Falls WA, Campeau S, Kim M (1993) Fear-potentiated startle: a neural and pharmacological analysis. Behav Brain Res 58:175-198

de Jong R, Groenink L, van der Gugten J, Olivier B (2002) The lightenhanced startle paradigm as a putative animal model of anxiety: effects of chlordiazepoxide, flesonoxan and fluvoxamine. Psychopharmacology 159:176-180

de Jongh R, Groenink L, van der Gugten J, Olivier B (2003) Lightenhanced and fear-potentiated startle: temporal characteristics and effects of alpha-helical corticotropin-releasing hormone. Biol Psychiatry 54:1041-1048

Diamant M, Croiset G, de Wied D (1992) The effect of corticotropinreleasing factor $(\mathrm{CRF})$ on autonomic and behavioral responses during shock-prod burying test in rats. Peptides 13:1149-1158

Effting M, Kindt M (2007) Contextual control of human fear associations in a renewal paradigm. Behav Res Ther 45:20022018

Filion DL, Dawson ME, Schell AM (1993) Modification of the acoustic startle-reflex eyeblink: a tool for investigating early and late attentional processes. Biol Psychol 35:185-200

Foa EB, Zinbarg R, Rothbaum BO (1992) Uncontrollability and unpredictability in post-traumatic stress disorder: an animal model. Psychol Bull 112(2):218-238

Frankland PW, Cestari V, Filipkowski RK, McDonald RJ, Silva AJ (1998) The dorsal hippocampus is essential for context discrimination but not for contextual conditioning. Behav Neurosci 112:863-874

Gewirtz JC, McNish KA, Davis M (1998) Lesions of the bed nucleus of the stria terminalis block sensitization of acoustic startle reflex produced by repeated stress, but not fear-potentiated startle. Prog Neuro-Psychopharmacol Biol Psychiatry 22:625-648

Gray JA, McNaughton N (2000) The neuropsychology of anxiety: an inquiry into the function of the Septo-Hippocampal System, 2nd edn. Oxford University Press, Oxford University Press

Grillon C, Ameli R (1998) Effects of threat of shock, shock electrode placement, and darkness on startle. Int J Psychophysiol 28:223-231

Grillon C, Baas JM (2002) Comments on the use of the startle reflex in psychopharmacological challenges: impact of baseline startle on measurement of fear-potentiated startle. Psychopharmacology $164: 236-238$

Grillon C, Baas JM (2003) A review of the modulation of startle by affective states and its application to psychiatry. Clin Neurophysiol 114:1557-1579

Grillon C, Davis M (1997) Fear-potentiated startle conditioning in humans: explicit and contextual cue conditioning following paired vs. unpaired training. Psychophysiology 34:451-458

Grillon C, Morgan CA (1999) Fear-potentiated startle conditioning to explicit and contextual cues in Gulf war veterans with posttraumatic stress disorder. J Abnorm Psychology 108:134-142

Grillon C, Ameli R, Woods SW, Merikangas K, Davis M (1991) Fearpotentiated startle in humans: effects of anticipatory anxiety on the acoustic blink reflex. Psychophysiology 28:588-595

Grillon C, Ameli R, Goddard A, Woods S, Davis M (1994) Baseline and fear-potentiated startle in panic disorder patients. Biol Psychiatry 35:431-439
Grillon C, Dierker L, Merikangas K (1997a) Startle modulation in children at risk for anxiety disorders and/or alcoholism. J Am Acad Child Adolesc Psych 36:925-932

Grillon C, Pellowski M, Merikangas KR, Davis M (1997b) Darkness facilitates the acoustic startle in humans. Biol Psychiatry 42: 453-460

Grillon C, Dierker L, Merikangas KR (1998a) Fear-potentiated startle in adolescents offspring at risk for anxiety disorder. Biol Psychiatry 44:990-997

Grillon C, Morgan CA, Davis M, Southwick SM (1998b) Effect of darkness on acoustic startle in Vietnam veterans with PTSD. Am J Psychiatr 155:812-817

Grillon C, Morgan CA, Davis M, Southwick SM (1998c) Effects of experimental context and explicit threat cues on acoustic startle in Vietnam veterans with posttraumatic stress disorder. Biol Psychiatry 44:1027-1036

Grillon C, Merikangas KR, Dierker L, Snidman N, Arriaga RI, Kagan J, Donzella B, Dikel T, Nelson C (1999) Startle potentiation by threat of aversive stimuli and darkness in adolescents: a multi-site study. Int J Psychophysiol 32:63-73

Grillon C, Baas JM, Lissek S, Smith K, Milstein J (2004) Anxious responses to predictable and unpredictable aversive events. Behav Neurosci 118:916-924

Grillon C, Warner V, Hille J, Merikangas KR, Bruder G, Tenke CE, Nomura Y, Leite P, Weissman MM (2005) Families at high and low risk for depression: a three-generation startle study. Biol Psychiatry 57:953-960

Grillon C, Baas JM, Pine DS, Lissek S, Lawley M, Ellis V, Levine J (2006a) The benzodiazepine alprazolam dissociates contextual fear from cued fear in humans as assessed by fear-potentiated startle. Biol Psychiatry 60:760-766

Grillon C, Baas JM, Cornwell BR, Johnson L (2006b) Context conditioning and behavioral avoidance in a virtual reality environment: effect of predictability. Biol Psychiatry 60:752-759

Grillon C, Duncko R, Covington MF, Kopperman L, Kling MA (2007) Acute stress potentiates anxiety in humans. Biol Psychiatry 62:1183-1186

Hackley SA, Graham FK (1987) Effects of attending selectively to the spatial position of reflex-eliciting and reflex-modulating stimuli. J Exp Psychol 13:411-424

Hammack SE, Richey KJ, Watkins LR, Maier SF (2004) Chemical lesion of the bed nucleus of the stria terminalis blocks the behavioral consequences of uncontrollable stress. Behav Neurosci 118:443-448

Harris JA, Westbrook RF (2001) Contextual control over the expression of fear in rats conditioned under a benzodiazepine. Psychopharmacology (Berl) 156:92-97

Hitchcock JM, Davis M (1986) Lesions of the amygdala, but not of the cerebellum or red nucleus, block conditioned fear as measured with the potentiated startle paradigm. Behav Neurosci 100:11-22

Hoehn TT, Braune SS, Scheibe GG, Albus MM (1997) Physiological, biochemical and subjective parameters in anxiety patients with panic disorder during stress exposure as compared with healthy controls. Eur Arch Psychiatry Clin Neurosci 247:264-274

Hollander E, Liebowitz MR, Gorman JM, Cohen B, Fyer A, Klein DF (1989) Cortisol and sodium lactate-induced panic. Arch Gen Psychiatry 46:135-140

Jennings PD, Schell AM, Filion DL, Dawson ME (1996) Tracking early and late stages of information processing: contributions of startle eyeblink reflex modification. Psychophysiology 33: $148-155$

Kessler RC, McGonagle KA, Zhao S, Nelson CB, Hughes M, Eshleman S, Wittchen H-U, Kendler KS (1994) Lifetime and 12-month prevalence of DSM-III-R psychiatric disorders in the United States. Arch Gen Psychiatry 51:8-19 
Kim JJ, Fanselow MS (1992) Modality-specific retrograde amnesia of fear. Science 256:675-677

Korte SM (2001) Corticosteroids in relation to fear, anxiety and psychopathology. Neurosci Biobehav Rev 25:117-142

Korte SM, De Boer SF (2003) A robust animal model of state anxiety: fear-potentiated behaviour in the elevated plus-maze. Eur J Pharmacol 463:163-175

Labar KS, Phelps EA (2005) Reinstatement of conditioned fear in humans is context dependent and impaired in amnesia. Behav Neurosci 119:677-686

Landis C, Hunt WA (1939) The startle pattern. Farrar and Rinehart: New York, pp 168

Lang PJ, Bradley MM, Cuthbert BN (1998) Emotion, motivation, and anxiety: brain mechanisms and psychophysiology. Biol Psychiatry 44:1248-1263

Lang PJ, Davis M, Ohman A (2000) Fear and anxiety: animal models and human cognitive psychophysiology. J Affect Disord 61: $137-159$

Lee Y, Davis M (1997) Role of the hippocampus, the bed nucleus of the stria terminalis, and the amygdala in the excitatory effect of corticotropin-releasing hormone on the acoustic startle reflex. J Neurosci 17:6434-6446

Lee Y, Schulkin J, Davis M (1994) Effect of corticosterone on the enhancement of the acoustic startle reflex by corticotropin releasing factor (CRF). Brain Res 666:93-98

Lejuez CW, Eifert GH, Zvolensky MJ, Richards JB (2000) Preference between onset predictable and unpredictable administrations of $20 \%$ carbon-dioxide-enriched air: implications for better understanding the etiology and treatment of panic disorder. J Exp Psychol Appl 6:349-358

Levitt EE, Persky H, Brady JP, Fitzgerald JA (1963) The effect of hydorcotisone infusion on hypnotically induced anxiety. Psychosom Med 25:158-161

Liang KC, Melia KR, Campeau S, Falls WA, Miserendino MJD, Davis M (1992) Lesions of the central nucleus of the amygdala, but not the paraventricular nucleus of the hypothalamus, block the excitatory effects of corticotropin-releasing factor on the acoustic startle reflex. J Neurosci 12:2313-2320

Liebowitz MR, Gorman JM, Fyer AJ, Levitt M, Dillon DJ, Levy G, Appleby I, Anderson S, Palij M, Davies S, Klein DF (1985) Lactate provocation of panic attacks. II. Biochemical and physiological findings. Arch Gen Psychiatry 42:709

Lissek S, Dvir S, Baas JMP, Mc Dowell DJ, Pine DS, Shaywitz E, Grillon C (2005) Pathological anxiety is associated with sustained anxiety to an unpredictably stressful context but not with phasic fear reactions to an explicit threat-cue 60th Annual Meeting of the Society of Biol Psychiatry, Atlanta, GA

Lovibond PF (1992) Tonic and phasic electrodermal measures of human aversive conditioning with long duration stimuli. Psychophysiology 29:621-632

Ludewig S, Ludewig K, Geyer MA, Hell D, Vollenweider FX (2002) Prepulse inhibition deficits in patients with panic disorder. Depress Anxiety 15:55-60

Maier SF (1991) Stressor controllability, cognition and fear. In: Madden JI (ed) Neurobiology of learning, emotion and affect. Raven, Ltd, New York, pp 159-193

Mak AS, Blewitt K, Heaven PCL (2004) Gender and personality influences in adolescent threat and challenge appraisals and depressive symptoms. Pers Indiv Diff 36:1483-1496

Makino S, Gold PW, Schulkin J (1994a) Corticosterone effects on corticotropin-releasing hormone mRNA in the central nucleus of the amygdala and the parvocellular region of the paraventricular nucleus of the hypothalamus. Brain Res 640:105-112

Makino S, Gold PW, Schulkin J (1994b) Effects of corticosterone on $\mathrm{CRH}$ mRNA and content in the bed nucleus of the stria terminalis; comparison with the effects in the central nucleus of the amygdala and the paraventricular nucleus of the hypothalamus. Brain Res 657:141-149

Masini CV, Sauer S, Campeau S (2005) Ferret odor as a processive stress model in rats: neurochemical, behavioral, and endocrine evidence. Behav Neurosci 119:280-292

McEwen BSBS (2005) Glucocorticoids, depression, and mood disorders: structural remodeling in the brain. Metab Clin Exp 54:20-23

McNish KA, Gewirtz JC, Davis M (1997) Evidence of contextual fear after lesions of the hippocampus: a disruption of freezing but not fear-potentiated startle. J Neurosci 17:9353-9360

McReynolds WT (1976) Anxiety as fear: a behavioral approach to one emotion. In: Zuckerman M, Spielberger CD (eds) Emotions and anxiety. Wiley, New York, pp 281-316

Millon T, Davis RD (1999) Developmental pathogenesis. In: Millon T, Davis RD (eds) Oxford textbook of psychopathology. Oxford University Press, New York, pp 29-48

Mineka S, Kihlstrom JF (1978) Unpredictable and uncontrollable events: a new perspective on experimental neurosis. J Abnorm Psychol 87:256-271

Moore CL, Morelli GA (1979) Mother rats interact differently with male and female offspring. J Comp Physiol Psychol 93:677-684

Morgan CA III, Grillon C, Southwick SM, Davis M, Charney DS (1995a) Fear-potentiated startle in posttraumatic stress disorder. Biol Psychiatry 38:378-385

Morgan CA III, Grillon C, Southwick SM, Nagy LM, Davis M, Krystal JH, Charney DS (1995b) Yohimbine facilitated acoustic startle in combat veterans with post-traumatic stress disorder. Psychopharmacology 117:466-471

Moses SN, Winocur G, Ryan JD, Moscovitch M (2007) Environmental complexity affects contextual fear conditioning following hippocampal lesions in rats. Hippocampus 17:333-337

Mowrer OOH, Aiken EEG (1954) Contiguity vs. drive-reduction in conditioned fear: temporal variations in conditioned and unconditioned stimulus. Am J Psychol 67:26-38

Neumann DLB (2006) The effects of physical context changes and multiple extinction contexts on two forms of renewal in a conditioned suppression task with humans. Learn Motiv 37: $149-175$

Neumann DL, Lipp OV, Cory SE (2007) Conducting extinction in multiple contexts does not necessarily attenuate the renewal of shock expectancy in a fear-conditioning procedure with humans. Behav Res Ther 45:385-394

Odling-Smee FJ (1975a) Background stimuli and the inter-stimulus interval during pavlovian conditioning. Q J Exp Psychol 27: 387-392

Odling-Smee FJ (1975b) The role of background stimuli during pavlovian conditioning. Q J Exp Psychol 27:201-209

Overmier JB, Wielkewicz RM (1983) On unpredictability as a causal factor in "learned helplessness". Learn Motiv 14:324-337

Parente AC, Garcia-Leal C, Del-Ben CM, Guimarães FS, Graeff FG (2005) Subjective and neurovegetative changes in healthy volunteers and panic patients performing simulated public speaking. Eur Neuropsychopharmacol 15:663-671

Patrick CJ, Bradley MM, Lang PJ (1993) Emotion in the criminal psychopath: startle reflex modulation. J Abnorm Psychology 102:82-92

Pentkowski NS, Blanchard DC, Lever C, Litvin Y, Blanchard RJ (2006) Effects of lesions to the dorsal and ventral hippocampus on defensive behaviors in rats. Eur J Neurosci 23:2185-2196

Phillips RG, LeDoux JE (1992) Differential contribution of amygdala and hippocampus to cued and contextual fear conditioning. Behav Neurosci 106:274-285

Pine DS, Klein RG, Roberson-Nay R, Mannuzza S, Moulton JL, Woldehawariat G, Guardino M (2005) Response to 5\% carbon dioxide in children and adolescents: relationship to panic disorder 
in parents and anxiety disorders in subjects. Arch Gen Psychiatry 62:73-80

Pole N, Neylan TC, Best SR, Orr SP, Marmar CR (2003) Fearpotentiated startle and posttraumatic stress symptoms in urban police officers. J Trauma Stress 16:471-479

Rachman ST (2004) Anxiety. Psychology Press: New York

Reid GM (1994) Maternal sex-stereotyping of newborns. Psychol Rep $75: 1443-1450$

Rescorla RA, Wagner AR (1972) A theory of Pavlovian conditioning: variations in the effectiveness of reinforcement and nonreinforcement. In: Black AH, Prokasy WF (eds) Classical conditioning II: current theory and research. Appleton-Century-Crofts, New York, pp 64-99

Rhudy JL, Meagher MW (2000) Fear and anxiety: divergent effects on human pain thresholds. Pain. 84:65-75

Riba J, Rodriguez-Fornells A, Urbano G, Antonijoan R, Barbanoj MJ (1999) Fear potentiated startle of the acoustic startle response is preserved after lorazepam administration to human subjects. Psychophysiology 36(Suppl 1):S94

Riba J, Rodriguez-Fornells A, Urbano G, Morte A, Antonijoan R, Barbanoj MJ (2001) Differential effects of alprazolam on the baseline and fear-potentiated startle reflex in humans: a doseresponse study. Psychopharmacology (Berl) 157:358-367

Richmond MA, Yee BK, Pouzet B, Veenman L, Rawlins JN, Feldon J, Bannerman DM (1999) Dissociating context and space within the hippocampus: effects of complete, dorsal, and ventral excitotoxic hippocampal lesions on conditioned freezing and spatial learning. Behav Neurosci 113:1189-1203

Risbrough VB, Stein MB (2006) Role of corticotropin releasing factor in anxiety disorders: a translational research perspective. Horm Behav 50:550-561

Risbrough VB, Hauger RL, Pelleymounter MA, Geyer MA (2003) Role of corticotropin releasing factor (CRF) receptors 1 and 2 in CRF-potentiated acoustic startle in mice. Psychopharmacology (Berl) 170:178-187

Risbrough VB, Coste S, Stenzel-Poore M, Wurts W, Hauger RL, Geyer MA (2007) Role of CRF-R1 and CRF-R2 receptors in unconditioned and conditioned fear-induced increases in startle. Sixty-second Annual Convention of the Society for Biol Psychiatry, San Diego, CA, pp 127S

Rodgers RJ (1997) Animal models of 'anxiety': where next? Behav Pharmacol 8:477-496

Sachar EJ (1970) Psychological factors relating to activation and inhibition of the adrenocortical stress response in man: a review. Prog Brain Res 32:316-324

Sananes CB, Davis M (1992) N-Methyl-D-Aspartate lesions of the lateral and basolateral nuclei of the amygdala block fearpotentiated startle and shock sensitization of startle. Behav Neurosci 106:72-80

Sarbin TR (1964) Anxiety: reification of a metaphor. Arch Gen Psychiatry 10:630-638

Scaife JJC, Langley RRW, Bradshaw CCM, Szabadi EE (2005) Diazepam suppresses the acquisition but not the expression of 'fear-potentiation' of the acoustic startle response in man. J Psychopharmacol 19:347-356

Schulkin J, Morgan MA, Rosen JB (2005) A neuroendocrine mechanism for sustaining fear. Trends Neurosci 28:629-635

Shea A, Walsh C, Macmillan H, Steiner M (2005) Child maltreatment and HPA axis dysregulation: relationship to major depressive disorder and post traumatic stress disorder in females. Psychoneuroendocrinology 30:162-178

Sherman JE, Kalin NH (1988) ICV-CRH alters stress-induced freezing behavior without affecting pain sensitivity. Pharmacol Biochem Behav 30:801-807
Staub E, Tursky B, Schwartz G (1971) Self-control and predictability: their effects on reactions to aversive stimulation. J Pers Soc Psychol 18:157-162

Straube T, Mentzel HJ, Miltner WH (2007) Waiting for spiders: brain activation during anticipatory anxiety in spider phobics. Neuroimage 37:1427-36

Sullivan GM, Apergis J, Bush DE, Johnson LR, Hou M, Ledoux JE (2004) Lesions in the bed nucleus of the stria terminalis disrupt corticosterone and freezing responses elicited by a contextual but not by a specific cue-conditioned fear stimulus. Neuroscience 128:7-14

Swanson LW, Simmons DM (1989) Differential steroid hormone and neural influences on peptide mRNA levels in CRH cells of the paraventricular nucleus: a hybridization histochemical study in the rat. J Comp Neurol 285:413-435

Swerdlow NR, Geyer MA, Vale WW, Koob GF (1986) Corticotropinreleasing factor potentiates acoustic startle in rats: blockade by chlordiazepoxide. Psychopharmacology 88:147-152

Toufexis D (2007) Region- and sex-specific modulation of anxiety behaviours in the rat. J Neuroendocrinol 19:461-473

Turner SM, Beidel DC, Roberson-Nay R (2005) Offspring of anxious parents: reactivity, habituation, and anxiety-proneness. Behav Res Ther 43:1263-1279

Vansteenwegen D, Hermans D, Vervliet B, Francken G, Beckers T, Baeyens F, Eelen P (2005) Return of fear in a human differential conditioning paradigm caused by a return to the original acquistion context. Behav Res Ther 43:323-336

Waddell J, Morris RW, Bouton ME (2006) Effects of bed nucleus of the stria terminalis lesions on conditioned anxiety: aversive conditioning with long-duration conditional stimuli and reinstatement of extinguished fear. Behav Neurosci 120:324-336

Walker D, Davis M (1997a) Double dissociation between the involvement of the bed nucleus of the stria terminalis and the central nucleus of the amygdala in startle increases produced by conditioned versus unconditioned fear. J Neurosci 17:93759383

Walker DL, Davis M (1997b) Anxiogenic effects of high illumination levels assessed with the acoustic startle response in rats. Biol Psychiatry 42:461-471

Walker DL, Davis M (2002a) Light-enhanced startle: further pharmacological and behavioral characterization. Psychopharmacology (Berl) 159:304-310

Walker DL, Davis M (2002b) Quantifying fear potentiated startle using absolute versus proportional increase scoring methods: implications for the neurocircuitry of fear and anxiety. Psychopharmacology (Berl) 164:318-28

Walker DL, Toufexis DJ, Davis M (2003) Role of the bed nucleus of the stria terminalis versus the amygdala in fear, stress, and anxiety. Eur J Pharmacol 463:199-216

Warburton DM (1974) Modern biochemical concepts of anxiety. Implications for psychopharmacological treatment. Int Pharmacopsychiatry 9:189-205

Winocur G (1997) Hippocampal lesions alter conditioning to conditional and contextual stimuli. Behav Brain Res 88:219-229

Woods SW, Charney DS, McPherson CA, Gradman AH, Heninger GR (1987) Situational panic attacks: behavioral, physiologic, and biochemical characterization. Arch Gen Psychiatry 44: $365-375$

Young EA, Abelson JL, Curtis GC, Nesse RM (1997) Childhood adversity and vulnerability to mood and anxiety disorders. Depress Anxiety 5:66-72

Zinbarg R, Barlow D (1996) Structure of anxiety and the anxiety disorders: a hierarchical model. J Abnorm Psychology 105: $181-193$ 